\title{
Comentario \\ Aleluya a la mentira. Dalton, Retamar y la campaña mediática contra Cuba
}

\section{Alpidio Alonso-GraU}

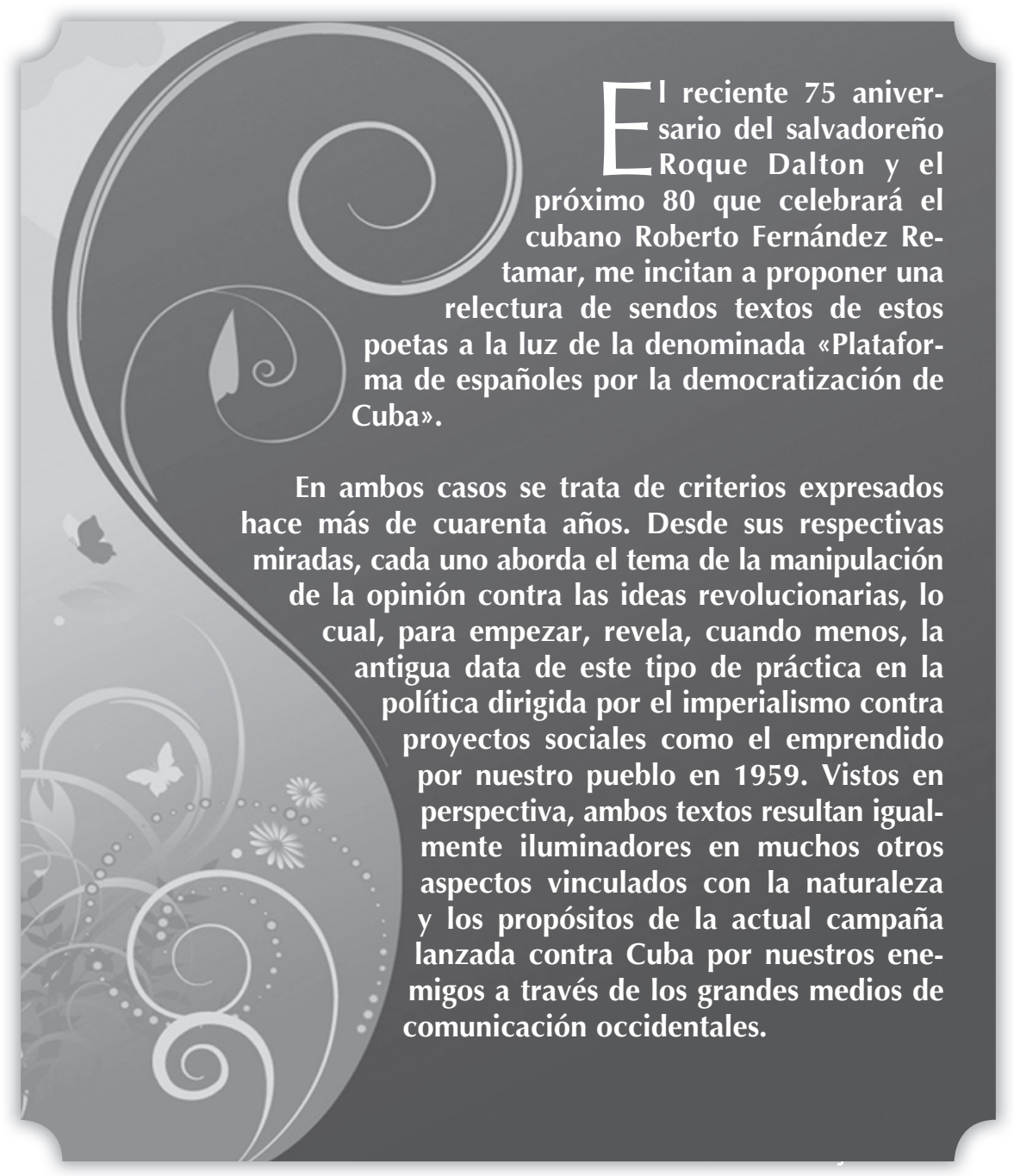


A raíz de que en 1969 Roque Dalton ganara el Premio Casa de las Américas con su libro de poemas Taberna y otros lugares, Mario Benedetti lo entrevistó para el semanario Marcha. Un simple repaso de algunos fragmentos extraídos de aquel diálogo resulta suficiente para ilustrar los mecanismos a través de los cuales se produce el fenómeno a que aludíamos más arriba. Sin necesidad de agregarle una coma para percibir su actualidad, cada una de las opiniones vertidas por Roque resulta una estocada a fondo contra el vedettismo y la postura realmente lamentable y oportunista de este grupo de intelectuales que hoy se junta en España para atacar a la Revolución Cubana desde supuestas posiciones democráticas. Llama asimismo la atención dentro de este análisis, la observación que hace el salvadoreño respecto a un fenómeno donde con frecuencia, de manera inconciente, no pocos intelectuales honestos son víctimas de la perversidad de esta maquinaria informativa puesta al servicio de los intereses de los poderosos:

MB: Así como decíamos que conviene estudiar la relación entre el escritor y el socialismo, dentro de un estado socialista, creo que también deberíamos estudiar los problemas derivados de la presencia de un escritor revolucionario dentro de una sociedad de impronta capitalista, o sea dentro de un mercado de consumo.

RD: Cuando apuntábamos que un escritor inserto en un país socialista puede caer en la tentación de la industria mundial del espectáculo editorial, o sea la industria que persigue la enajenación de las masas populares, estábamos señalando un peligro real pero también excepcional. En cambio el escritor que trabaja en el mundo capitalista, vive inmerso en una situación presidida por un gran aparato que por lo general está al servicio de la ideología del enemigo, y por lo tanto corre el riesgo de convertirse en su víctima inmediata. Aun el escritor que se rebela, aun el escritor que es digno de su papel y lucha contra la enajenación, puede ser una víctima de ese aparataje y ser aludido desde diferentes niveles.

MB: Algo así como una "operación seducción».

RD: O una "operación soborno", que incluye maniobras destinadas a dotarlo de una buena conciencia a pesar de las concesiones que poco a poco se le puedan arrancar. 
Todo está destinado a un fin último: asimilarlo al gran aparato de enajenación, montado en contra de nuestras masas populares.

MB: El mero hecho de neutralizarlo, ¿no es acaso un buen dividendo para el enemigo?

RD: Desde luego, en este aspecto el enemigo ejerce una acción cotidiana, costosísima, que se manifiesta en todos los órdenes de la vida cultural: ediciones lujosas, excelente promoción del libro, gloria efímera, la posibilidad de convertirse en una suerte de prostituta intelectual, muy bien pagada, o un payaso simpático, al servicio de los intereses más inconfesables, aunque a veces, en los mejores y más inocentes de los casos, no se tenga conciencia de ello. Lo que me produce preocupación es que tales maniobras de seducción alcancen a muchos de nuestros compañeros y que éstos no adviertan que al caer en la falta de seriedad, en la payasada, o en, las concesiones directas al enemigo, están contribuyendo a crear en los pueblos la imagen de que al intelectual promedio sólo le interesa la frivolidad, la publicidad, la tontería.

En fecha aún más temprana a la de la publicación de estos razonamientos de Roque, el 7 de septiembre de 1959 Roberto Fernández Retamar dio a conocer en el periódico Revolución su artículo «Elogio de la mentira», en que aborda el tema de la manipulación intencionada de la información, específicamente contra la Revolución Cubana, por parte de los que ya entonces Ilamó «alquilones internacionales de la pluma».

En este artículo Retamar parte de diferenciar la mentira del error. El error, como la verdad, puede, según expresa, «nacer de la buena fe. Ambos, error y verdad, están de un mismo lado». A lo que más adelante agrega:

Mentira no es sólo decir A por B. Hay que ver la rica gama de la mentira, de la cual esa suplantación no es más que un caso particular. Mentira es presentar la parte por el todo, mentira es decir lo malo y callar lo bueno, mentira es seguir usando un mismo nombre para designar cosas que sabemos que han cambiado de esencia, mentira es subrayar lo negativo pequeño y dejar en brumas lo positivo grande, mentira es mezclar lo verdadero a lo dudoso para que lo 
dudoso parezca verdadero también, mentira es dar una opinión pasajera por regla fija de conducta, mentira es... pero ¿quién podría intentar agotar las variedades camaleónicas de entidad tan rica en posibilidades? La verdad es pobre, pues no es más que una; la mentira es millonaria. Mentira es todo lo que sabemos que no es verdad y damos como si lo fuera. En eso estriba la diferencia con el error: el que mantiene un error cree tener una verdad, el que mantiene una mentira sabe que no tiene una verdad. El primero actúa de buena fe; el segundo, de mala fe [...] Quien miente sabe ya dónde está la verdad; quien miente realiza un homenaje, todo lo extraño que se quiera, a la verdad. Los mentirosos son también heraldos de la verdad. Los equivocados la niegan; los mentirosos proclaman, al echar mano de la mentira, que saben dónde está la verdad [...] Si se ven obligados a recurrir a un arsenal tan endeble, es que hasta ellos, nuestros enemigos $-y$ son enemigos porque ellos lo han escogido así, porque, al parecer, de eso viven-, reconocen que la verdad está de nuestro lado, que a ellos no les han quedado en las alforjas sino unas cuantas (o unas muchas) mentiras oxidadas y romas. [...] Pero al ir a refutar esas imposturas hemos dado con un fenómeno en verdad curioso. Esas mentiras son la prueba palpable de que los que tratan de dañarnos saben, ellos también, que tenemos razón. A través de sus frágiles telas, esas mentiras van proclamando al mundo que no tienen sino mentiras contra nosotros, que la verdad va con nosotros.

Precisamente porque sabemos que quienes hoy desde España encabezan una nueva campaña difamatoria y abiertamente injerencista contra nuestro país, omiten o tergiversan una verdad que de sobra conocen, y que de ellos no podemos esperar otra cosa que mentiras y acusaciones mal intencionadas dirigidas a confundir a quienes por desinformación, en cualquier parte, pueden ser víctimas del engaño, es que nos vemos obligados a responderles. ¿Qué, si no odio, podemos aspirar a recibir de ellos? Permeados por una ideología raigalmente colonialista e «incapacitados vitalmente para admirar» una obra brotada del más elevado sacrificio, representan, como diría Lezama, «el escudo de las más viejas decadencias». Por eso no nos asombran la dimensión del engaño ni el ensañamiento con que asumen su triste papel.

Hay otra España, lo sabemos. Y es precisamente a esa otra España 
entrañable y solidaria a la que tanto debemos y respetamos los cubanos, a la primera que ofenden las maniobras serviles de quienes, de manera absolutamente insultante, pretenden erigirse en generosos consejeros de nuestro destino.

Para quienes hoy nos atacan con plena conciencia de lo que hacen -lo sabemos de antemano-, ninguno de nuestros argumentos resultará nunca suficiente. Su objetivo no es el de dialogar o establecer un debate para propiciar, como pérfidamente aducen, algún posible entendimiento. Su meta es otra -la misma desde los años en que Retamar y Roque denunciaron, en los textos citados, actitudes semejantes-, y harían cualquier cosa para alcanzarla: destruir la Revolución y retrotraernos al capitalismo. No es por tanto a estos asalariados nuncios de la maldad a quienes nos dirigimos, sino a quienes, de buena fe, pudieran estar confundidos.

Trato de ponerme en el lugar de los que nos agreden y comprendo las razones profundas de su preocupación: ni las Damas de Blanco, ni la vida de Fariñas, ni siquiera la suerte de sus mercenarios dentro de la Isla, presos o en libertad, constituyen cuestiones que realmente les preocupan. Ellas son, en todo caso, meros pretextos para encauzar objetivos mucho más profundos. Lo que en verdad los enloquece es constatar que a pesar de todas las presiones y dificultades a que nos han sometido durante más de cincuenta años, no han logrado hacernos retroceder en nuestros propósitos de construir un proyecto social y político propio, ni han podido, por más que lo han intentado, arrancarnos una sola concesión de principios en nuestra determinación de construir el socialismo y en nuestra aspiración legítima de, a través de él, llegar a "alcanzar toda la justicia». Aun cuando no lo manifiesten, ellos saben muy bien cómo piensa la abrumadora mayoría de los cubanos. Aunque busquen la manera de minimizarlo casi hasta el silencio en sus grandes medios, saben también interpretar el simbolismo de una manifestación como la protagonizada en todo el país el pasado $1^{\circ}$ de mayo y lo que significa el masivo respaldo que dio el pueblo a la Revolución en las urnas durante las últimas elecciones.

Pero sus preocupaciones no terminan con lo que, muy a su pesar, hemos logrado hasta el presente. Más que todo, es nuestro futuro lo que se les convierte en un insoportable dolor de cabeza. Saber que nos las hemos arreglado para salir de los peores momentos de la crisis y ver que empiezan a darse cambios, reales, tangibles, en función de hacer más eficiente nuestra economía, desburocratizar estructuras, fortalecer nuestra institucionalidad y en definitiva, encauzar nuestro socialismo por caminos ajustados a nuestras posibilidades y aspiraciones, sin dejarle la más mí- 
nima brecha a los anexionistas y a quienes apuestan por acabar con lo que tanto sacrificio nos ha costado, es ya demasiado para quienes han vivido para impedirlo y han convertido al «tema cubano» en una obsesión, en un enfermizo asunto sentimental dentro de sus vidas. Si algo saben quienes hoy nos calumnian y exigen cambios a toda costa al gobierno cubano, es precisamente que esos cambios empezaron ya, que se están haciendo, solo que al ritmo que nuestras posibilidades y las actuales circunstancias nos lo permiten, y a nuestra manera, para no cometer errores que, a la postre, resultarían imperdonables.

$\mathrm{Si}$ algo queremos los revolucionarios cubanos es ver materializados ya todos los cambios que se han proyectado para superar las dificultades por las que atravesamos, muchas de ellas, motivadas por nosotros mismos, derivadas de errores e irresponsabilidades imputables solo a nuestra desidia y al excesivo paternalismo del Estado. Pero por encima de nuestros deseos está la responsabilidad que tenemos con asegurar que no se dé un solo paso en falso, pues si de algo estamos conscientes es de la dimensión de lo que nos estamos jugando. Justamente por eso es que están tan preocupados. Ellos saben lo que significan esos cambios para el fortalecimiento de nuestro socialismo, temen a nuestros cambios porque saben que haciéndolos les quitamos la posibilidad de que puedan meter las manos en nuestro futuro. De nuevo nos subestimaron pensando que no podríamos. Tan ensimismados han estado durante años con su pregón acerca de nuestro «inmovilismo», que han terminado entrampados en su propio discurso, sorprendidos por una realidad que, ahora sí, los aterra. La capacidad dialéctica que ha mostrado la Revolución, su audacia para actuar aun en medio de las complejas condiciones de crisis que vive el mundo, evidentemente, no estaba en sus planes.

Sobre esto, me detengo en un matiz que me parece esencial: es cierto que las presiones externas, en primerísimo lugar el bloqueo norteamericano, generan dificultades que nos hacen mucho más difícil poder materializar los cambios que nos hemos planteado realizar los cubanos para hacer más eficiente y justo el sistema que hemos elegido. Mas creo importante subrayar que, independientemente de las presiones externas, la voluntad de producir esos cambios dentro de nuestro socialismo ha sido claramente expresada desde el barrio hasta la más alta dirección de la Revolución; que se trata de cambios que obedecen a necesidades planteadas por los propios cubanos, quienes deberemos, ateniéndonos a las condiciones de cada momento, encontrar las fórmulas más adecuadas para llevarlos a la práctica. Con esto quiero decir que no serán, por tanto, ni presiones intimidatorias, 
ni campañas injerencistas como la que se ha montado por estos días desde España, ni la posición común de la Unión Europea, ni siquiera el bloqueo yanqui, quienes decidirán nuestro futuro. Nuestro futuro depende de la lucidez, la capacidad y el coraje que demostremos los cubanos para seguir defendiendo un modelo de socialismo propio, independientemente de lo que hagan y piensen nuestros enemigos en cualquier parte.

Muy mal encaminados andaríamos, si confiáramos nuestra capacidad para obrar en función de mejorar nuestra sociedad y construir nuestro porvenir a la benevolencia y los buenos oficios de quienes, desde el mismo primer día, han hecho hasta lo imposible para tratar de impedirlo.

Todo esto sin hablar del papel jugado por Cuba en la gestación y consolidación del Alba como alternativa de integración en un contexto internacional en que las principales potencias imperialistas no hallan ya qué hacer con la crisis que su propia codicia ha provocado. Tampoco con esto parecen haber contado quienes, a juzgar por las maniobras que hacen para aislarnos -en la Unión Europea y otros foros internacionales-, se muestran muy preocupados con el modo en que los cubanos hemos logrado hacer viable un modelo de intercambio que promete expandirse por la región y que ha elevado el prestigio de Cuba y la simpatía por su pueblo a niveles nunca antes vistos.

A la luz de esa realidad, donde junto a Cuba varios países de nuestro continente comienzan a dirimir su destino sin necesidad de rendirles cuentas, como era usual hace apenas unos pocos años, puede comprenderse la incomodidad de quienes en España y las viejas metrópolis no han superado los obsoletos y bochornosos criterios coloniales en su visión sobre cuál debe ser su relación con Cuba y el resto de sus antiguas colonias.

Todo eso y más está detrás de esta nueva diatriba mediática presentada en España contra Cuba por un pequeño grupo de intelectuales. Son los mismos. La impotencia y la infamia de los hartos de siempre, contra la dignidad y los sueños de un pueblo humilde y bravo.

Tal vez ellos no lo han pensado, pero, a su modo, y sobre todo conociendo de quiénes viene, esta nueva campaña llega para ofrecernos otra certeza de que los cubanos hemos elegido el rumbo correcto. Por ello, al valorar el modo en que sus maniobras se revertirán en favor de nuestra causa, sumándole, por supuesto, todo lo que de aprendizaje y experiencia dejan para los revolucionarios cubanos, podemos darles las gracias a nuestros «generosos enemigos», y junto al poeta celebrar el favor que vienen a hacernos sus mentiras: 


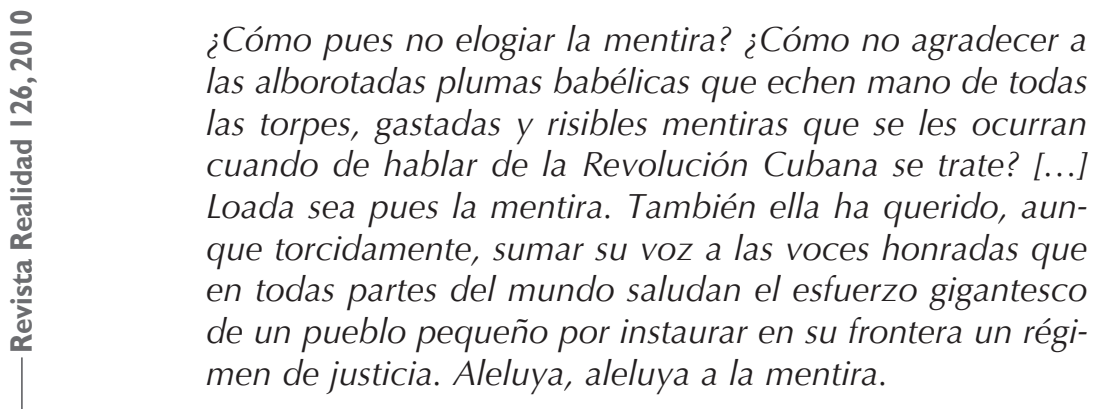

